
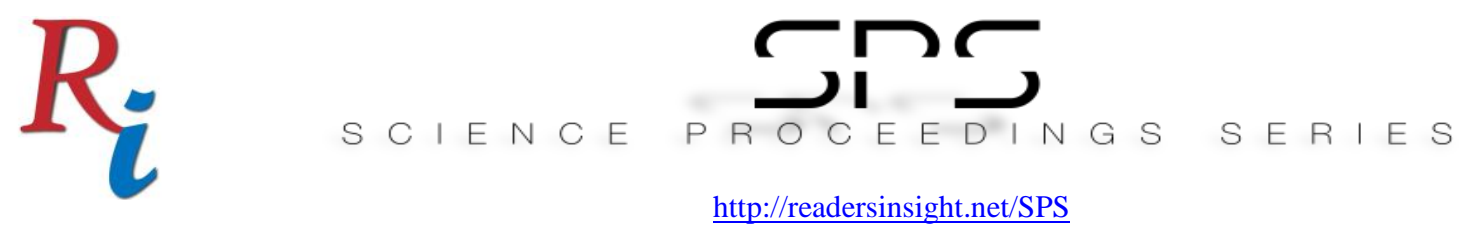

\title{
CRITERIA FOR ACCEPTING SOFTWARE REQUIREMENTS NEGOTIATION TOOLS IN THE SOFTWARE INDUSTRY
}

\author{
Shamsu Abdullahi* \\ Department of Software Engineering \\ University of Malaya, Kualar Lumpur Malaysia \\ Sasalihawa09@gmail.com
}

\begin{abstract}
Abubakar Zakari
Kano State University of science and Technology,

Nigeria

Abubakar.zakari@yahoo.com

Amina Nura

Departement of Mathematics and Computer Science Umaru Musa Yaradua University, Katsina, Nigeria

Amina.nura@umyu.edu.ng
\end{abstract}

\section{Abdulfatah Samaila Mashasha}

Department of Software Engineering

Katsina Institute of Technology and Management, Nigeria

abdulfatahsamaila@gmail.com

\section{Haruna Abdu}

Department of Computer Science, Federal University Lokaja, Nigeria

Haruna.abdu@fulokoja.edu.ng

\section{Salisu Suleiman}

Department of Computer Science

Isa Kaita College of Education Dutsina, Nigeria

salisusuleiman@gmail.com

*Corrosponding author's Email: sasalihawa09@gmail.com

Peer-review under responsibility of 4th Asia International Multidisciplinary Conference 2020 Scientific Committee http://connectingasia.org/scientific-committee/

(C) 2020 Published by Readers Insight Publisher, lat 306 Savoy Residencia, Block 3 F11/1,44000 Islamabad. Pakistan, editor@readersinsight.net 


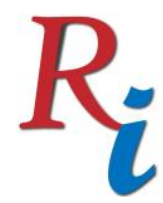

\section{A b s tract}

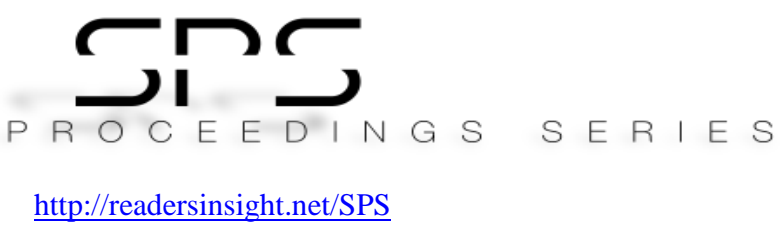

Requirements negotiation is a centralized process of making a decision in order to resolve conflicts in the requirements of the stakeholder. The negotiation will enable the shared vision of software to be developed among the heterogeneous stakeholder in the software industry to be achieved. Many process models used for the negotiation of stakeholder's requirements have been proposed for the software industry by the research community, yet the acceptance of these process models is discouraging. This study tends to investigate the inadequate adoption of requirements negotiation process models. Further, it finds the acceptance criteria for the software industry to adopt requirements negotiation models. Finding shows that the software industries do not adopt the process models. The perceived usefulness, perceived ease of use and many more criteria have been identified through the literature review on the general criteria of software systems acceptance.

Keywords: Criteria, Decision- Making, Requirements, Negotiation, Stakeholders, Models

\section{Rese a r ch H igh I ight s}

The negotiation will enables the shared vision of software to be developed among the heterogeneous stakeholder in the software industry to be achieved[1]. The occurrence of conflicts increases as stakeholders such as developers, acquirers, users, and maintainers pursue mismatching goals[2]. The result of negotiation is set to satisfies two or more negotiation participants in the presence of limited common knowledge and conflicting preferences [3, 4]. Many software projects have failed due to poor requirements negotiation among stakeholders [5]. The automated negotiation tools proposed to the software industry for requirements negotiation include win-win easywin-win, MPARN and so on[4]. Although numerous advanced researches exist in requirement negotiation that had been proven to enable software development industries carry out a structured requirement negotiation, yet the acceptance from the software industries is discouraging. There is no studies that investigate the cause of the rejection of these tools and acceptance criteria for software industries. This research sought to investigate the reason for the rejection of requirements negotiation solutions and identify criteria for the software industries to accept requirements negotiation tools. Finding shows that acceptance of automated tool of requirements negotiation is poor. Consequently, there exist many criteria for the software industry to accept requirements negotiation system

\section{Research Objectives}

The objectives of this research 

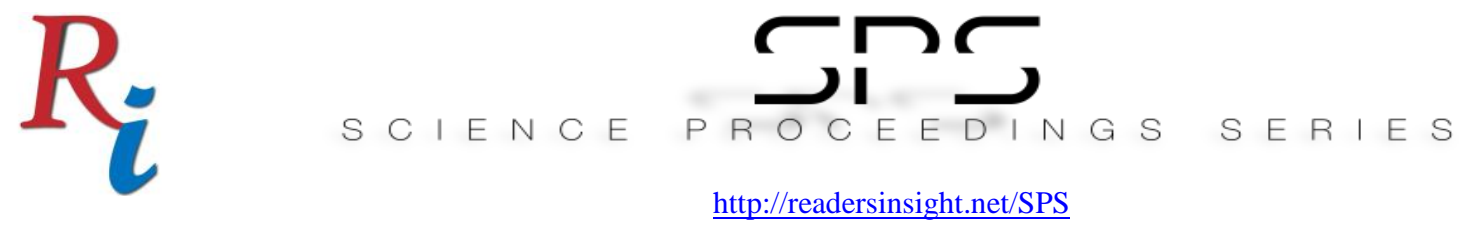

1. To investigate the reason for the rejection of requirements negotiation solutions in the software industry

2. Identify criteria of acceptance for the software industries to accept requirements negotiation tools

\section{Methodology}

This section presents the methodology adopted in this research. The guidelines of the study are depicted in Figure 1.

\section{Planning}

In this section, the authors initiate the research process by structuring the scope including the research questions, a survey with the participants from the software industry and analysis on the general criteria which make the user accept the software system. The criteria of software acceptance were recommended in the requirements negotiation for the software industries. This section originates the foundation of the methodology in this research.

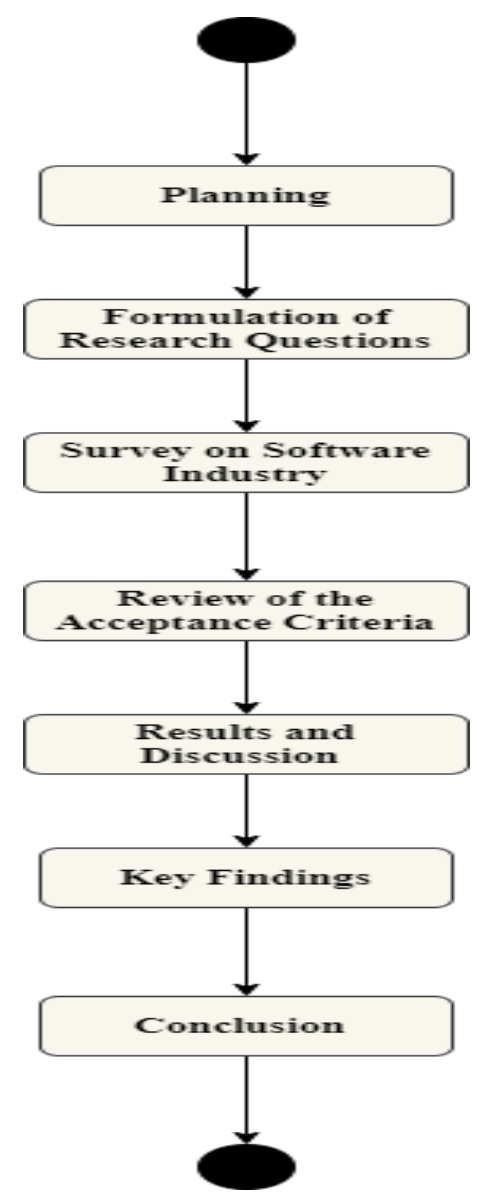

Figure 1: Research Methodology 


\section{$R_{i}$}

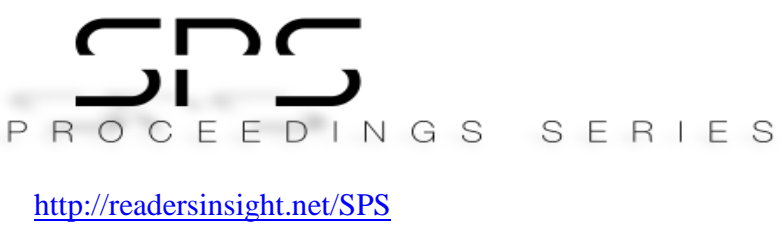

\section{Research Question}

The research questions (RQs) are formulated based on the motivation for addressing the study research objective. Table 1 listed the RQs along with their respective justifications

Table1: Research Questions and their rationale

\begin{tabular}{|l|l|l|}
\hline RQs & Research Question & Rationale \\
\hline RQ1 & $\begin{array}{l}\text { Do software industries adopt } \\
\text { requirements negotiation tools to } \\
\text { achieve agreements between the } \\
\text { stakeholders? }\end{array}$ & $\begin{array}{l}\text { To identify whether the software } \\
\text { industries are adopting requirements } \\
\text { negotiation tools }\end{array}$ \\
\hline RQ2 & $\begin{array}{l}\text { What are their criteria of accepting } \\
\text { requirement negotiation tool in the } \\
\text { software industry }\end{array}$ & $\begin{array}{l}\text { To investigate the criteria for software } \\
\text { industries to accept requirements } \\
\text { negotiation tools. }\end{array}$ \\
\hline
\end{tabular}

\section{Survey on software Industries}

This study survey 22 stakeholders from the software industry. These stakeholders are selected randomly so as to ensure proper representation of all stakeholders. Hence, stakeholders in the industry have equal chances of being selected to participate in the survey. The google form of the survey was sent online to the participants from the companies selected to participate in this research. The companies involved in the survey include software development Industries that specialize in the development of software systems, IT Development companies which provide the software development inside the organizations and IT consulting companies that provide guidance services to other IT companies

\section{Review on the criteria of system acceptance}

In an initiative to get the software industries to accept the requirements negotiation tool, this research performs a literature review on the criteria which influence users to accept software systems. The search string was formulated and manipulated on the electronic databases which include Google scholar, Science direct, Scopus, and dimension. Literature search results show many studies which adopts criteria in order to make users accept the software system.

The research findings from the literature indicate that many factors influence the decision of the users when they are presented with a new software package [6]. These factors are subjective norms, attitude and perceived behavioral control.

\section{Results}

RQ1: Do software industries adopt requirements negotiation tools to achieve agreements between the stakeholders? 


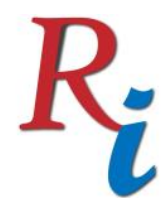

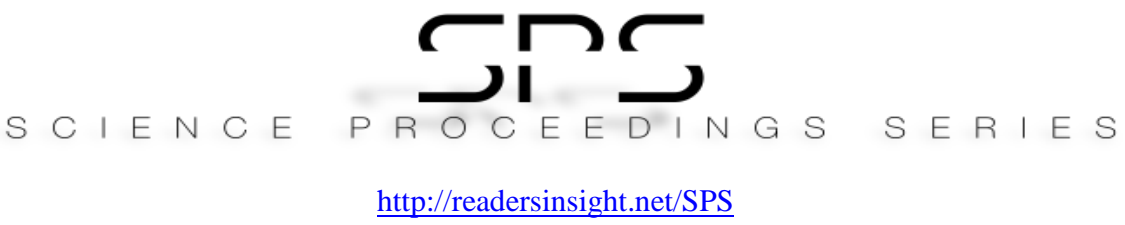

http://readersinsight.net/SPS

This RQ investigates the perception of the stakeholders regarding the adoption of requirements negotiation tools in their industries. The finding shows that from 22 respondents, $91 \%$ (20) participants stated that they negotiate requirements manually as presented in Figure 2. However, 9\% (2) respondents used automated requirements negotiation tools in their industries.

The reasons for not adopting the tools as stated by the majority of participants is as follows:

1. The tools are expensive to acquire,

2. Tools are not available in the market for the software industries to acquire.

3. Selected option of the stakeholders is often not be the right option for the decision-makers in the software industry.

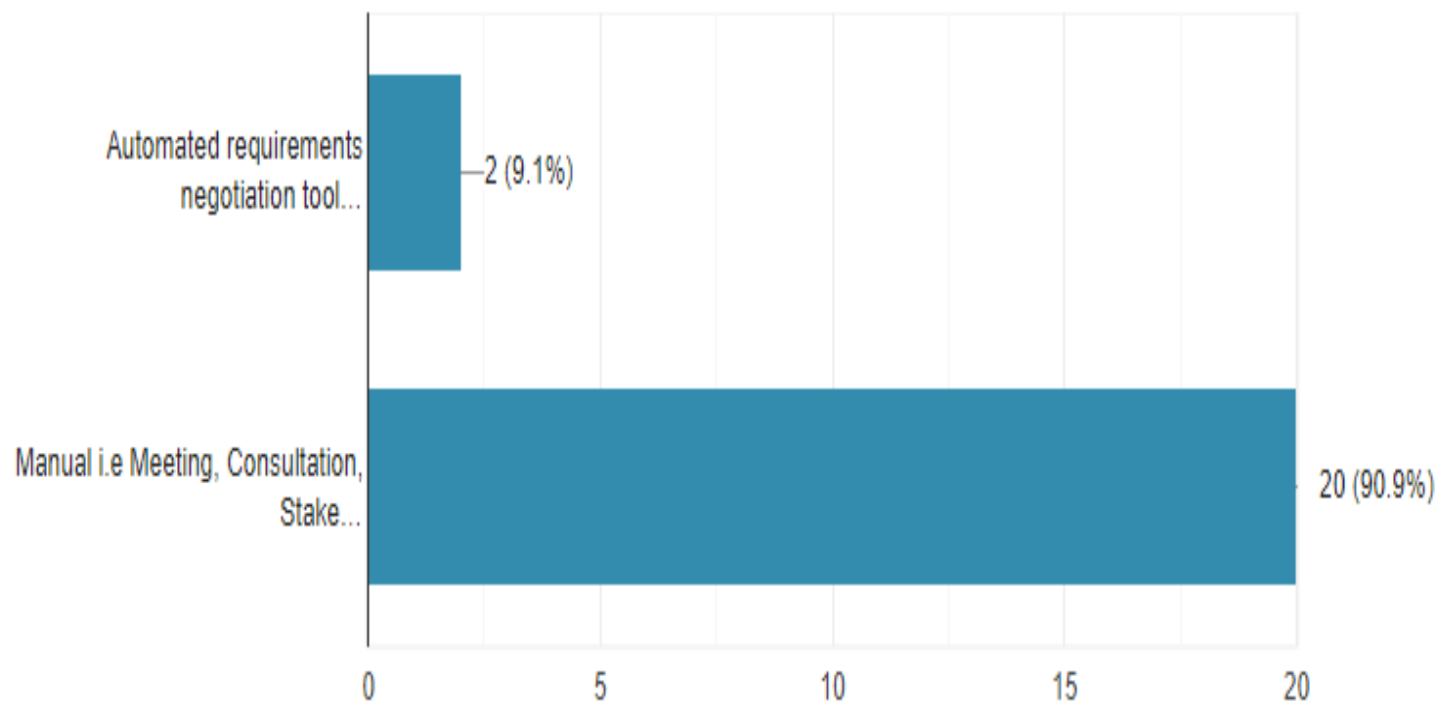

Figure 2: Mode of Negotiation in the Software Industry

RQ2: What are their criteria for accepting requirement negotiation tool in the software industry?

The general criteria for accepting a software system are suggested by this study be strictly adhere to while proposing the requirements negotiation tools to the software industries for the tools to be accepted. Each of the factors that determine the acceptance of the software system by the user earlier explained contain many criteria that can be adopted in the requirement negotiation research domain. This include Perceived Usefulness, Perceived ease of use, Perceived Risk, Compatibility, Interpersonal influence, External influence, Facilitating Condition, Satisfaction 
$R_{i}$

\section{Findings}

- Finding shows that the software industries have not been adopting requirements negotiation tools despite the large number proposed by the researchers due the intereset of the sponsors to be present in the development process.

- Survey results indicates that requirements negotiation tools are rejected by the industry due to mismatching goals of the decision-makers and stakeholders based on the selected options.

- Review of the literature proves the existence of many criteria which may influenced the software industries accept requirements negotiation tools.

- Interpersonal influence criteria in the requirements negotiation tools will make the top management accept the tools. Th is is because the tools are rejected by the top managements in software industry.

\section{Acknowledgement}

The study of Shamsu Abdullahi in University of Malaya is sponsored by Tertiary Education Trust Fund Nigeria through Department of Computer Science Hassan Usman Katsina Polytechnic, Katsina State, Nigeria

\section{REFERENCES}

[1] Ahmad, S., I.E.A. Jalil, and S.S.S. Ahmad, An Enhancement of Software Requirements Negotiation with Rule-based Reasoning: A Conceptual Model. Journal of Telecommunication, Electronic and Computer Engineering (JTEC), 2016. 8(10): p. 193198.

[2] Grünbacher, P. and N. Seyff, Requirements negotiation, in Engineering and managing software requirements. 2005, Springer. p. 143-162.

[3] Braun, P., et al., E-negotiation systems and software agents: Methods, models, and applications, in Intelligent decision-making support systems. 2006, Springer. p. 271-300.

[4] Sofian, H.B., et al., A requirements negotiation process model that integrates EasyWinWin with quality assurance and multi-criteria preference techniques. 2014. 39(6): p. 4667-4681.

[5] In, H.P. and D.J.J.U. Olson, Requirements Negotiation Using Multi-Criteria Preference Analysis. 2004. 10(4): p. 306-325. 

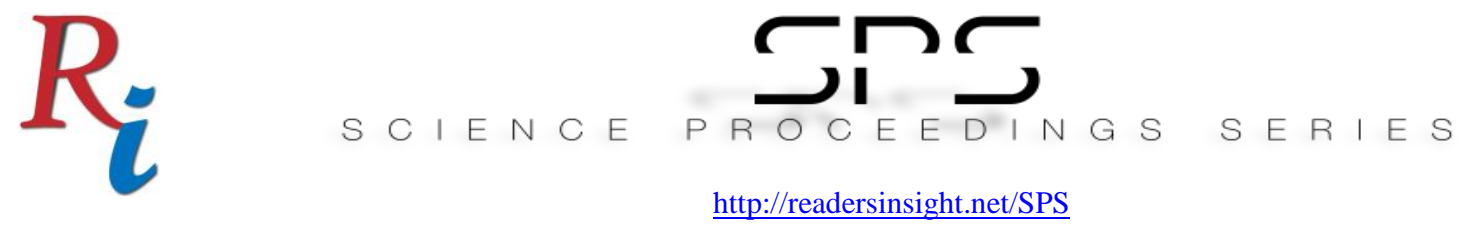

[6] Hung, S.-Y., C.-M. Chang, and T.-J.J.G.I.Q. Yu, Determinants of user acceptance of the e-Government services: The case of online tax filing and payment system. 2006. 23(1): p. $97-122$.

[7] Heirman, W. and M.J.P. Walrave, Predicting adolescent perpetration in cyberbullying: An application of the theory of planned behavior. 2012. 24(4): p. 614-620.

[8] Ajzen, I., Attitudes, traits, and actions: Dispositional prediction of behavior in personality and social psychology, in Advances in experimental social psychology. 1987, Elsevier. p. 1-63.

[9] Xia, W. and G. Lee. The influence of persuasion, training and experience on user perceptions and acceptance of IT innovation. in Proceedings of the twenty first international conference on Information systems. 2000. Association for Information Systems.

[10] Huang, J., et al. Social Recommendation with Interpersonal Influence. in ECAI. 2010. 